\title{
Diffusional Transport of Macromolecules in Developing Nerve Processes
}

\author{
Sergey Popova and Mu-ming Poo \\ Department of Biological Sciences, Columbia University, New York, New York 10027
}

\begin{abstract}
Passive transport of macromolecules in growing nerve processes was analyzed quantitatively by measuring the rate of diffusion of fluorescently labeled molecules injected into the soma of cultured Xenopus neurons. We found that the diffusion of globular proteins in the neurite's cytoplasm was about five times slower than that in aqueous solution, a rate considerably higher than those inferred from previous studies on cultured non-neuronal cells. The dependence of the diffusion coefficient, $D$, on the size of diffusing molecules was examined by measuring the diffusional spread of fluorescently labeled dextrans over a wide range of molecular weights. We found that the size dependence of $D$ deviates considerably from that expected for diffusion in a viscous aqueous medium: larger dextrans encounter disproportionately higher viscous resistance. Treatment of the neuron with the microfilament-disrupting agent cytochalasin B, or preloading of the cells with dephospho-synapsin I, a molecule that induces bundling of actin filaments, significantly increased the diffusion rate for large dextrans without affecting that of small dextrans. Taken together, these results provide a quantitative basis for assessing diffusion as a potential transport mechanism along nerve processes, and suggest that the microfilament meshwork imposes a selective constraint on the diffusion of large macromolecular components within the neuronal cytoplasm.
\end{abstract}

A prominent feature of the neuronal organization is the extensive distance between the site of macromolecular synthesis and the cellular destination for many of the synthesized components. In the mature neuron, various forms of active axonal transport are required to deliver the soluble and membrane-bound components to and from the distal regions of nerve processes (see review, Vale, 1987). Diffusional transport, whose rate decreases with the square of the distance, rapidly becomes an inefficient mechanism for molecular transport in long axons. On the other hand, diffusion could be effective for delivering soluble components to the dendrites, with transport distances on the order of hundreds of micrometers. Similarly, diffusion along developing neurites is likely to be an efficient form of transport before

\footnotetext{
Received May 31, 1991; revised Aug. 1, 1991; accepted Aug. 5, 1991.

We thank C. Scheffey and A. Brown for help with image analysis, and Bai Lu for providing synapsin-injected embryos. This work was supported by grants from National Institutes of Health (NS-22764) and Office of Naval Research (N0001490J-1865).

Correspondence should be addressed to Dr. Mu-ming Poo, Department of Biological Sciences, Columbia University, New York, NY 10027

a On leave from Department of Bioelectrochemistry, Institute of Electrochemistry, Academy of Sciences USSR, Moscow, USSR.

Copyright (C) 1992 Society for Neuroscience $0270-6474 / 92 / 120077-09 \$ 05.00 / 0$
}

extensive growth of the neurite and/or prior to the development of mature active transport mechanisms.

No quantitative measurement has previously been made on macromolecular diffusion along nerve processes, although many studies have provided information on diffusion within the cytoplasm of non-neuronal cells (Wojcieszyn et al., 1981; Wang et al., 1982; Salmon et al., 1984). The method used in the above studies, namely, fluorescence recovery after photobleaching (FRAP), addresses diffusion over short distances on the order of micrometers. It is not clear whether FRAP results can be readily applied for description of long-range diffusion in nerve cells. In the present study, we aimed to develop a quantitative method for measuring long-range molecular diffusion within the neuron, to assess the diffusion rate of macromolecules of various sizes, and to understand the cytoskeletal organization that sets the limit on the efficiency of diffusional transport. The information obtained is crucial for a reliable assessment of diffusional transport of neuronal macromolecules within the developing neuron. The knowledge of the cytoskeletal constraint on macromolecular movements will also be useful for understanding active transport processes.

\section{Materials and Methods \\ Cell culture}

Dissociated Xenopus nerve-muscle cultures were prepared according to methods reported previously (Spitzer and Lamborghini, 1976; Anderson and Cohen, 1977). Briefly, neural tube and myotomal tissue were dissociated in $\mathrm{Ca}^{2+}-\mathrm{Mg}^{2+}$-free solution $(58.2 \mathrm{mM} \mathrm{NaCl}, 0.7 \mathrm{mM} \mathrm{KCl}$, $0.3 \mathrm{~mm}$ EDTA, $\mathrm{pH} 7.4$ ). Dissociated cells were plated on the surface of clean glass coverslips. The cultures were kept at $20^{\circ} \mathrm{C}$ in a culture medium consisting of $50 \%$ (v/v) Leibovitz L-15 medium (GIBCO), $2 \%(\mathrm{v} /$ v) fetal bovine serum (GIBCO), $48 \%$ amphibian Ringer's solution (115 $\mathrm{mm} \mathrm{NaCl}, 2 \mathrm{~mm} \mathrm{CaCl}_{2}, 2.5 \mathrm{~mm} \mathrm{KCl}, 10 \mathrm{~mm}$ HEPES, pH 7.3). During the first day of culture, many spinal neurons develop extensive neuritic processes (Tabti and Poo, 1991).

\section{Fluorescent chemicals and microinjection}

Fluorescein isothiocyanate (FITC)-conjugated bovine serum albumin and lactalbumin, and tetramethylrhodamine (TRITC)-conjugated ovalbumin were from Molecular Probes (Eugene, OR). Dextrans conjugated with FITC or TRITC were purchased from Sigma. The purchased large molecular weight (MW) fluorescently labeled dextran samples $(150,500$, and $2000 \mathrm{~K}$ ) were further fractionated on a Sepharose column (CL-4B, Pharmacia Fine Chemicals). Elution of FITC-dextrans was monitored by absorbance at $495 \mathrm{~nm}$. The fraction at the center of absorbance peak was collected for microinjection. Labeled molecules were loaded into the neuron by using a whole-cell patch-clamp recording micropipette filled with internal solution ( $150 \mathrm{~mm} \mathrm{KCl}, 1 \mathrm{mM} \mathrm{NaCl}, 1 \mathrm{~mm} \mathrm{MgCl}$, $10 \mathrm{~mm}$ HEPES-KOH, pH 7.2) containing labeled molecules (5-20 mg/ $\mathrm{ml}$ ). After whole-cell recording condition was achieved by conventional methods (Hamill et al., 1981), using a patch-clamp amplifier (List EPC7), a pulse of positive pressure was applied through the pipette to inject a small amount of intrapipette solution into the neuron. No detectable 
change in the diameter of the soma was observed after the injection. The volume of injected solution was estimated by the method of Graessmann et al. (1980) to be less than $5 \%$ of the volume of the soma. The pressure injection method was used since it allows rapid loading of a sufficient quantity of molecules into the neuron. The recording pipette was removed immediately after the injection. To minimize the damage to the neuron and to simplify the subsequent analysis of the data, the time of contact of the pipette with the soma was kept as short as possible (usually less than $10 \mathrm{sec}$ ). Video recording of the fluorescence images began 10-30 sec following the injection.

In some experiments, dephosphorylated synapsin I protein was preloaded into the spinal neurons by injection of the synapsin I, together with TRITC-labeled dextran (MW $70 \mathrm{~K}$ ), into one of the blastomeres of the two to eight cell stage embryos (Sanes and Poo, 1989; B. Lu, P. Greengard, M-m. Poo, unpublished observations). The injected embryos were allowed to develop for $1 \mathrm{~d}$ and then used for culture preparation as described above. This procedure yielded dissociated spinal neurons containing exogenous synapsin $I$, identified by the presence of fluorescent marker TRITC-dextran. Previous Western blot analysis has shown that a substantial amount of synapsin I remained in the embryo $2 \mathrm{~d}$ after blastomere injection (Lu, Greengard, and Poo, unpublished observations). For experiments involving cytochalasin, cytochalasin B (Sigma) was diluted 1000 -fold from a stock solution in dimethyl sulfoxide to give a final concentration of $10 \mu \mathrm{g} / \mathrm{ml}$.

\section{Quantitative fluorescence microscopy and image processing}

The cells were examined with a Zeiss microscope equipped with phasecontrast or epifluorescence optics, using $40 \times$ (NA 0.75 ) water immersion lens. The images were collected by either a silicon-intensified target (SIT) camera (RCA, TC1030) or an intensified CCD camera (Quantex, QX-100) operating at fixed gain, displayed on a video monitor, and recorded in VHS videotape recorder (JVC, HR-D600U). The recorded images were analyzed by means of a digital image processor (Imaging Technology Inc., series 151). The images were "grabbed" as an array of $512 \times 512$ pixels with 256 gray levels. Typically 32 or 64 frames were averaged for quantitative analysis. The distribution of fluorescence intensity was obtained by measuring the total intensity within rectangular sampling areas $\left(3 \times 3\right.$ pixels, $\left.0.9 \times 1.2 \mu \mathrm{m}^{2}\right)$ along the length of the neurite. The sampling started at the hillock of the neurite, with regular spacing of 2-5 $\mu \mathrm{m}$ along the length of the neurite. The background fluorescence, which was measured at cell-free areas a few micrometers away from the corresponding spots at the neurite, was subtracted from each measurement at the neurite. This subtraction procedure was chosen to minimize the error due to leakage of fluorescence molecules from the patch pipette to the extracellular medium before highresistance seal was achieved.

\section{Analysis of diffusion process}

Diffusion along neuritic processes. The diffusional spread of injected molecules from the soma to the neuritic processes was analyzed as a one-dimensional diffusion from an infinite source, assuming the concentration of the injected molecule in the soma remained constant during the diffusion process. Let $C(x, t)$ be the concentration of injected molecules at distance $x$ from the soma at time $t$ after the injection. The above assumptions led to the following conditions: $C(x=0, t)=C_{\mathrm{o}}$ and $C^{\prime}(x>0, t=0)=0$. The solution of one-dimensional diffusion equation yields (Crank, 1975)

$$
C(x, t)=C_{\mathrm{o}}\left(1-\operatorname{erf} \frac{x}{2 \sqrt{D t}}\right),
$$

where $D$ is the diffusion coefficient, and erf is error function given by $\operatorname{erf}(y)=\frac{2}{\sqrt{\pi}} \int_{0}^{y} \exp \left(-z^{2}\right) d z$

Equation 1 was used to fit the experimentally measured profile of fluorescence intensity along the neurite at various times after the injection by least-square fit. For each time point a $D$ value was determined. The average of $D$ over three to eight different time points was taken as the best-fit $D$ value. Because of the nonuniformity and branching of neurites, in most cases experimental data over relatively short lengths of the neurite (30-80 $\mu \mathrm{m}$ from the soma) were analyzed.

In the above analysis, we assumed that experimentally measured fluorescence intensity at the given point is proportional to the concentration of the labeled molecules. Self-quenching of the fluorescence is negligible at the concentration of fluorescence label used $(<1 \mathrm{~mm})$. The assumption of infinite source of injected molecules at the soma is valid if the concentration of labeled molecules in the soma does not decrease substantially due to the diffusion of the molecules in the neurite. This was true for short neurites and/or for short durations after injection. Experimentally, we have observed that the fluorescence intensity at the neuritic hillock did not decrease more than $10 \%$ during the entire course of the experiment. The initial condition $C(x>0, t=0)=0$, that is, no labeled molecules present in the neurite beyond the hillock immediately after injection, is acceptable when the duration of injection is much shorter than the time at which the measurement of diffusion is made. The extent of photobleaching of the injected fluorophores was less than $5 \%$ for a typical experiment (total time of illumination, $<1$ $\mathrm{min})$. The nonlinearity of the SIT camera was estimated according to (Stolberg and Fraser, 1988; Spring and Lowy, 1989) to be no more than $5 \%$.

Diffusion in aqueous solution. The diffusion coefficient of fluorescently labeled molecules in aqueous solution was determined by monitoring the diffusional spread of focally ejected labeled molecules in a solution used for whole-cell recording (see Fluorescent chemicals and microinjections). A micropipette was filled with solution containing $5-50 \mathrm{mg}$ $\mathrm{ml}$ of labeled molecules, and its tip was brought close to the surface of a glass coverslip located at the bottom of a Petri dish. To measure $D$ of labeled proteins, the coverslip was pretreated with bovine serum albumin for $2-4 \mathrm{hr}(10 \mathrm{mg} / \mathrm{ml}$ in Ringer's solution) to avoid binding of the proteins to the glass surface. A single pressure pulse of duration 10$30 \mathrm{msec}$ was applied to the pipette, using a picospritzer (model II, General Valve). The spread of fluorescence was monitored with an SIT or intensified CCD camera and recorded on videotape. The distribution of fluorescence intensity was digitized $5-15 \mathrm{sec}$ after ejection, a time much longer than the duration of ejection. The distances at which the diffusional spread was measured were much larger $(\sim 100 \mu \mathrm{m})$ than the initial size of ejected volume. In this case, the initial condition of diffusion can be approximated by a point source located at the site of ejection. The solution of diffusion equation for a point source in threedimensional infinite volume is given by Crank (1975)

$$
C(x, t)=A \frac{\exp \left(-x^{2} / 4 D t\right)}{(D t)^{3 / 2}}
$$

where $C(x, t)$ is the concentration of the molecule at the distance $x$ from the tip of the pipette at time $t$ after the ejection, $D$ is the diffusion coefficient, and $A$ is a constant. Equation 2 was used to obtain a $D$ value by the procedure of least-square fit. A similar approach was used to measure macromolecule release from polymers into fluids of different viscosities (Radomsky et al., 1990). In the above analysis, we assumed that only fluorescence intensity from the focal planc was measured. Model calculations demonstrated that even in the case when the lens collects all of the off-focus fluorescence, the error introduced in the estimate of $D$ is less than $5 \%$.

\section{Results}

\section{Measurement of the diffusion cocfficient}

The experiments were carried out on isolated neurons bearing one or a few neuritic processes in 1-d-old Xenopus cell cultures. Fluorescently labeled macromolecules were loaded into the soma of the neuron using the gigaohm seal, whole-cell recording technique (see Materials and Methods). Figure 1 depicts the recorded images at three different times following a pulse injection of FITC-labeled BSA. Immediately after injection, labeled BSA molecules were confined mainly to the soma of the neuron. Within minutes, the molecules had spread along the neurite and reached the growth cone. In general, the fluorescence images of the neurite were recorded for 3-5 sec duration at an interval of $15 \mathrm{sec}$. The fluorescence intensity was digitized and analyzed to determine the diffusion coefficient $(D)$. Figure 2 illustrates the measured concentration distribution of injected BSA at four different time points in a typical experiment. The solid curves represent theoretically predicted diffusion profiles for a $D$ value of $10.1 \mu \mathrm{m}^{2} / \mathrm{sec}$ obtained by the procedure of least-square fit 

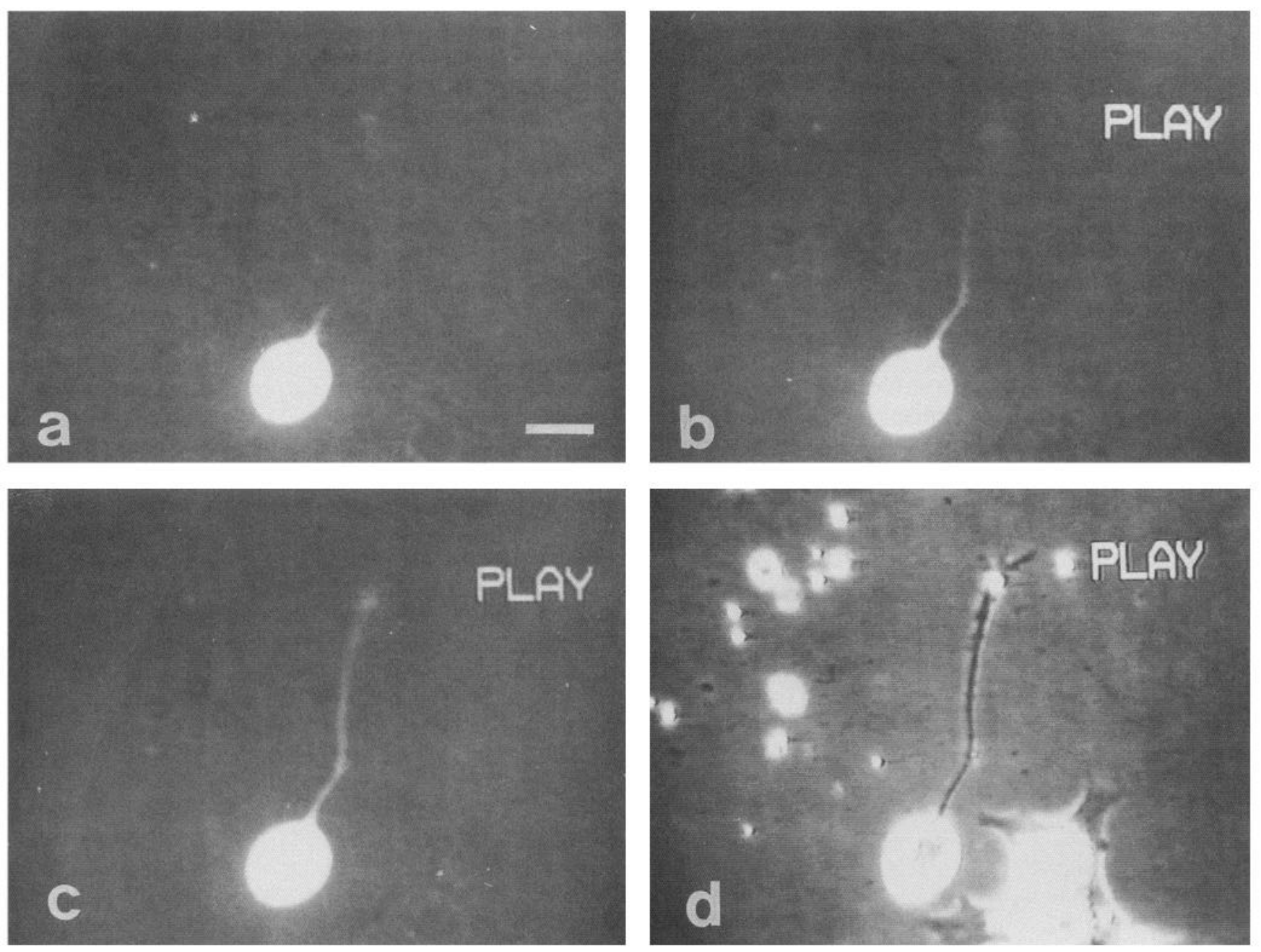

Figure 1. Diffusion of FITC-conjugated BSA injected into the soma of a neuron in Xenopus culture. $a-c$, Fluorescence micrographs of the neuron taken at $15 \mathrm{sec}, 1 \mathrm{~min}$, and $3 \mathrm{~min}$ after injection, respectively. $d$, Phase-contrast micrograph taken at $3 \mathrm{~min}$ after injection. Scale bar, $20 \mu \mathrm{m}$.

(see Materials and Methods). This method was used for routine measurements of diffusion rates.

As a first-order approximation, the value of $D$ can also be estimated from experimental curves without the curve-fitting procedure. For a pure diffusional spread, the value of $D$ can be obtained by a simple formula, $D \sim x^{2} / t$, where $x$ is the distance for the fluorescence intensity to drop to one-half of the initial level at time $t$ after injection. For the example shown in Figure 2 , at $25 \mathrm{sec}$ after ejection the distance for the intensity to drop to one-half level is $\sim 17 \mu \mathrm{m}$ and $D \sim 17^{2} / 25 \sim 12 \mu \mathrm{m}^{2} / \mathrm{sec}$. The average $D$ value determined this way for all four time points was $9.5 \mu \mathrm{m}^{2} / \mathrm{sec}$. This is close to the value of $10.1 \mu \mathrm{m}^{2} / \mathrm{sec}$ found by the more rigorous approach described above. Both the routine rigorous method and the above rough estimate are based on the assumption that the concentration in the soma of injected molecules does not decrease substantially during the time of experiment. Since this assumption is valid for relatively short neurites and/or small times after injection (see Materials and Methods), the experimental data were analyzed for short initial segments of the neurite (30-80 $\mu \mathrm{m}$ from the soma).

A different approach that utilizes the information of diffusional spread over longer distances is to monitor the increase in concentration of the fluorescently labeled molecules with time at a number of fixed points along the neurite and determine $D$ by best-fit analysis, as illustrated in Figure 3 for the diffusional spread of FITC-lactalbumin. The data depict the increase in fluorescence intensity with time at three points along the neurite, that is, 54, 110, and $160 \mu \mathrm{m}$ from the soma. Best-fit analysis yielded a $D$ value of $25.2 \mu \mathrm{m}^{2} / \mathrm{sec}$. The result obtained by this method was consistent with those obtained routinely by analyzing the diffusion over short segments on neurites (see Table 1).

\section{Diffusion of globular proteins}

The diffusion coefficients of FITC- or TRITC-labeled BSA, ovalbumin, and lactalbumin along neurite processes were determined for a number of neurons in $1 \mathrm{~d}$ Xenopus cultures. The results are shown in Table 1 . As predicted by the Stokes-Einstein equation, $D=k T / 6 \pi \eta r$ (where $k$ is the Boltzmann constant, $T$ is absolute temperature, and $\eta$ is the viscosity of the medium), the average $D$ values were approximately inversely proportional to the radius ( $r$ ) of the protein, assuming globular conformation of these proteins in the cytoplasm. This size dependence of diffusion coefficient suggests that globular proteins with molecular weights in the range $15-60 \mathrm{~K}$ encounter an environment 


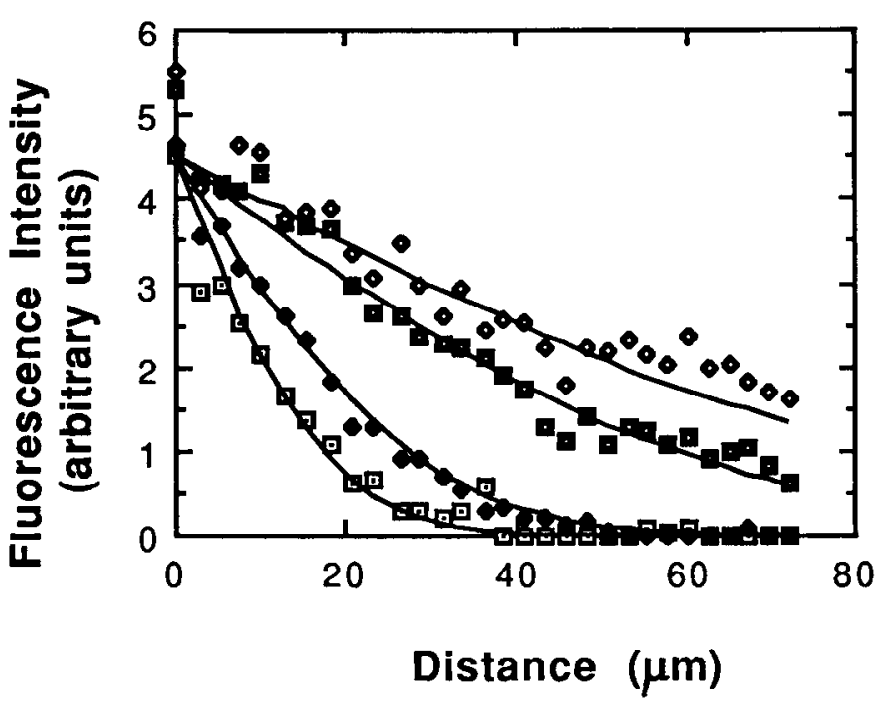

Figure 2. Fluorescence intensity distribution along the neurite. The diffusion profiles along the neurite at $10(\square), 25(\diamond), 115(\square)$, and 235 $\sec (\diamond)$ after injection of FITC-conjugated BSA were obtained by measuring the fluorescence intensity. Data points represent total intensity over $0.9 \times 1.2 \mu \mathrm{m}^{2}$ sampling areas along the neurite. The experimental data for each time point were used to determine a $D$ value by leastsquare fit with Equation 1 (see Materials and Methods). The average of four $D$ values was taken as the best-fit value. The solid lines shown are theoretical profiles of fluorescence distribution predicted by a single bestfit $D$ value of $10.1 \mu \mathrm{m}^{2} / \mathrm{sec}$.

of roughly the same viscosity, which is in the range of 5.2-5.9 centipoise (cP).

An independent approach was used to estimate the viscosity of the neurite cytoplasm, $\eta_{c}$, from the diffusion coefficient of the protein in neurites, $D_{c}$, assuming no information is available concerning the conformation of the protein. In this method, the diffusion coefficient of a protein in water, $D_{w}$, was measured and the viscosity of the cytoplasm, $\eta_{c}$, was taken as $\eta_{c}=\eta_{w}\left(D_{w} / D_{c}\right)$. The diffusion rates of three proteins were measured by monitoring the spread of fluorescence intensity after a pulse ejection of concentrated solution of labeled proteins from a micropipette to an aqueous solution (see Materials and Methods). The result of a typical experiment is presented in Figure 4. The best fit of diffusion profiles to the theoretical prediction yielded a $D$ value of $68.0 \mu \mathrm{m}^{2} / \mathrm{sec}$ for this experiment. The results of all the experiments on BSA, ovalbumin, and lactalbumin are summarized in Table 1. The ratios of $D_{c} / D_{w}$ found for three proteins

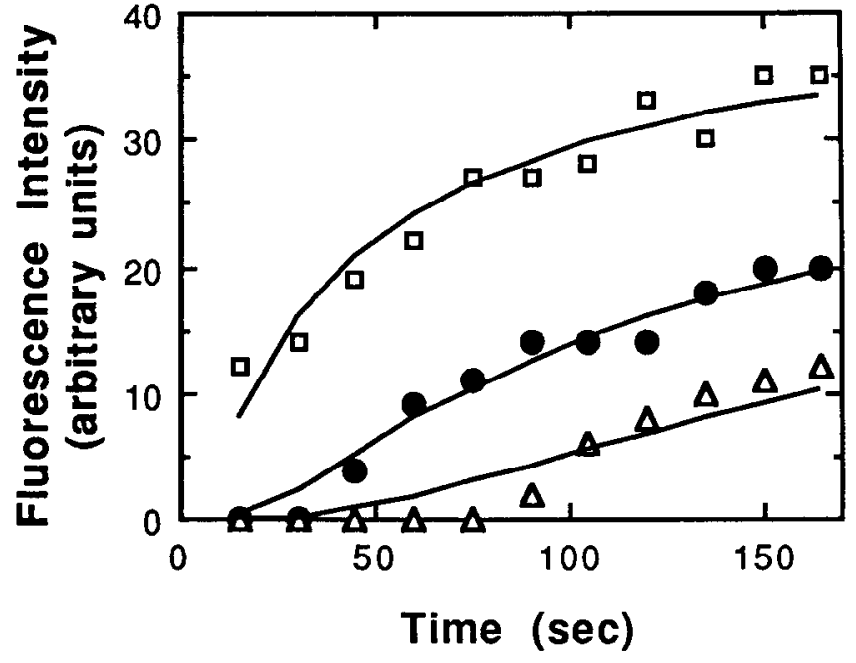

Figure 3. Changes in the fluorescence intensity of FITC-lactalbumin with time for three points along the neurite, that is, 54 (ㄷ), $110(\bullet)$, and $160 \mu \mathrm{m}(\Delta)$ from the soma. The solid lines are theoretically predicted changes in the concentration of injected molecules for a best-fit $D$ value of $25.2 \mu \mathrm{m}^{2} / \mathrm{sec}$.

were all close to $0.2(0.19-0.23)$, suggesting that within the neuronal cytoplasm these proteins encounter an environment of effective viscosity fivefold higher than that of the aqueous solution, or $5 \mathrm{cP}$. It is interesting to note that although our $D_{w}$ values are close to those reported previously for these proteins in aqueous solutions (Wang et al., 1982), the $D_{c}$ values for diffusion in neurites were 10 times higher than those reported in fibroblasts (Wojcieszyn et al., 1981).

\section{Diffusion of dextrans of different sizes}

To understand the factors that determine the rate of macromolecular diffusion in neurites, we undertook a systematic study of the diffusion of chemically uniform molecules of different sizes in the neuronal cytoplasm. Fluorescently labeled dextrans were chosen because of their inert nature and the availability of dextrans of a wide range of molecular weight. The size of the molecules can be empirically defined by the effective hydrodynamic radius of the molecules $(r)$, which is related to the measured diffusion coefficient in a homogeneous isotropic medium by the Stokes-Einstein equation (Table 2). The $r$ of dextrans used in our experiments varied from 2.0 to $44.8 \mathrm{~nm}$. These

Table 1. Diffusion coefficients of globular proteins in neurite cytoplasm and in aqueous solution

\begin{tabular}{|c|c|c|c|c|}
\hline & $\begin{array}{l}\text { Molecular } \\
\text { weight }\end{array}$ & $\begin{array}{l}\text { Diffusion } \\
\text { coefficient in water } \\
\left(D_{w}, \mu \mathrm{m}^{2} / \mathrm{sec}\right)\end{array}$ & $\begin{array}{l}\text { Diffusion } \\
\text { coefficient in } \\
\text { nerve cytoplasm } \\
\left(D_{c}, \mu \mathrm{m}^{2} / \mathrm{sec}\right)\end{array}$ & $D_{c} / D_{w}$ \\
\hline Lactalbumin & $15 \mathrm{~K}$ & $\begin{array}{l}22.8 \pm 1.7 \\
(9)\end{array}$ & $\begin{array}{l}97.8 \pm 2.6 \\
(7)\end{array}$ & $0.23 \pm 0.02$ \\
\hline Ovalbumin & $45 \mathrm{~K}$ & $\begin{array}{l}15.8 \pm 2.1 \\
(6)\end{array}$ & $\begin{array}{l}79.1 \pm 2.6 \\
(9)\end{array}$ & $0.20 \pm 0.03$ \\
\hline BSA & $60 \mathrm{~K}$ & $\begin{array}{l}12.6 \pm 1.5 \\
(9)\end{array}$ & $\begin{array}{l}67.7 \pm 2.9 \\
(8)\end{array}$ & $0.19 \pm 0.03$ \\
\hline
\end{tabular}

Diffusion coefficients are listed as mean \pm SEM. The numbers in parentheses refer to the number of diffusion experiments analyzed. 


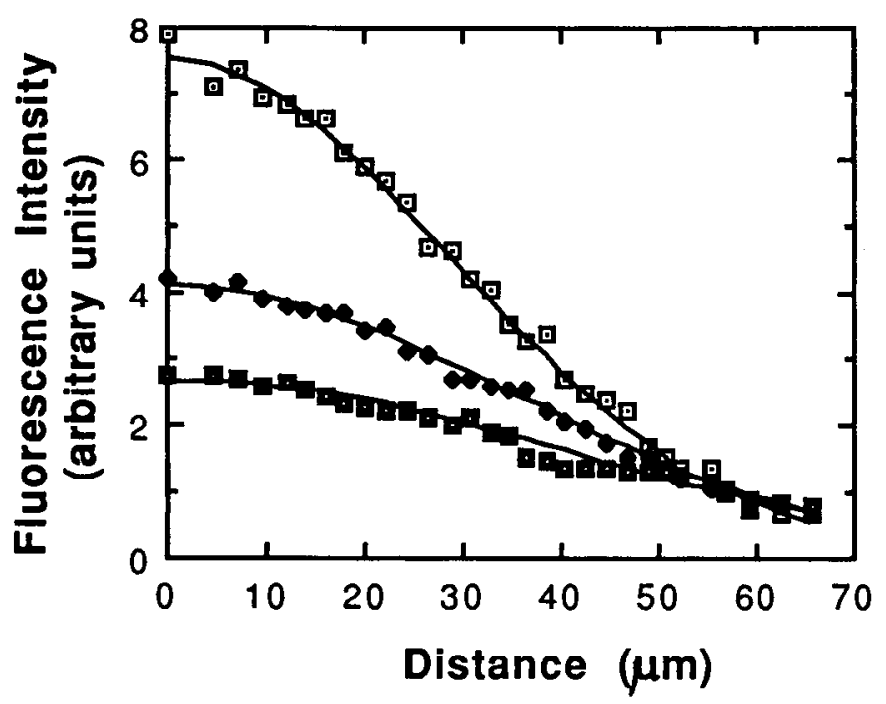

Figure 4. Diffusion of FITC-labeled BSA in the aqueous solution. The fluorescence intensity distribution was measured $6(\square), 9(\diamond)$, and 12 sec (घ) after a single pressure-pulse ejection of concentrated FITC-BSA solution from a micropipette into the aqueous medium (see Materials and Methods). The solid lines are theoretically predicted intensity profiles for the diffusional spread of the BSA from a point source, using a best-fit $D$ value of $68.0 \mu \mathrm{m}^{2} / \mathrm{sec}$.

inert molecules were used to measure coefficient of diffusion in the neurons.

Fluorescently labeled dextrans of different hydrodynamic radii were injected into the soma of neurons, and their diffusional spread along the neurite was measured. We found that the rate of diffusion depends much more strongly on the size of the molecules than that found in aqueous solution (Table 2). The ratio of the diffusion coefficient in the neurite cytoplasm $\left(D_{c}\right)$ to the diffusion coefficient in aqueous solution $\left(D_{w}\right)$ decreased with increasing sizes of dextrans (Fig. 5). Thus, when the wide range of molecular sizes is considered, the apparent viscosity of the neuronal cytoplasm depends on the size of the probe, a behavior that is characteristic of a non-Newtonian fluid.

Some theoretical models for the diffusion of probe molecules in cytoplasm predict the existence of critical size: the molecules whose radii are larger than critical will be entrapped in the cytoskeleton meshwork (Luby-Phelps et al., 1988). In our experiments, we did not find any cutoff size. Even large MW dextrans $(r=25.8 \mathrm{~nm})$ diffused from the soma to the end of the axon and penetrated into the growth cone (Fig. 6).

\section{Effects of cytochalasin B and synapsin I}

To understand what factors determine the increase in effective viscosity for large dextrans, we pretreated the cells with cytochalasin B for $\mathbf{l}$ hr to disrupt actin microfilaments. No effect on $D$ was found for low MW dextrans $(r=2.0 \mathrm{~nm})$, while $D$ for large dextrans $(r=25.8 \mathrm{~nm}$ ) increased 2.4 times (Table 3). The role of cytoskeleton on the diffusion of the dextrans was further studied by examining the effect of synapsin $I$, which is known to induce bundling of actin filaments (Bahler and Greengard, 1987). Dephosphorylated synapsin I molecules were preloaded into the neurons by injecting (together with TRITCdextran, MW $70 \mathrm{~K}$ ) into one of the blastomeres of the Xenopus embryo. We found that $D$ of low MW dextran did not differ in control versus synapsin I-injected cells while $D$ of high MW

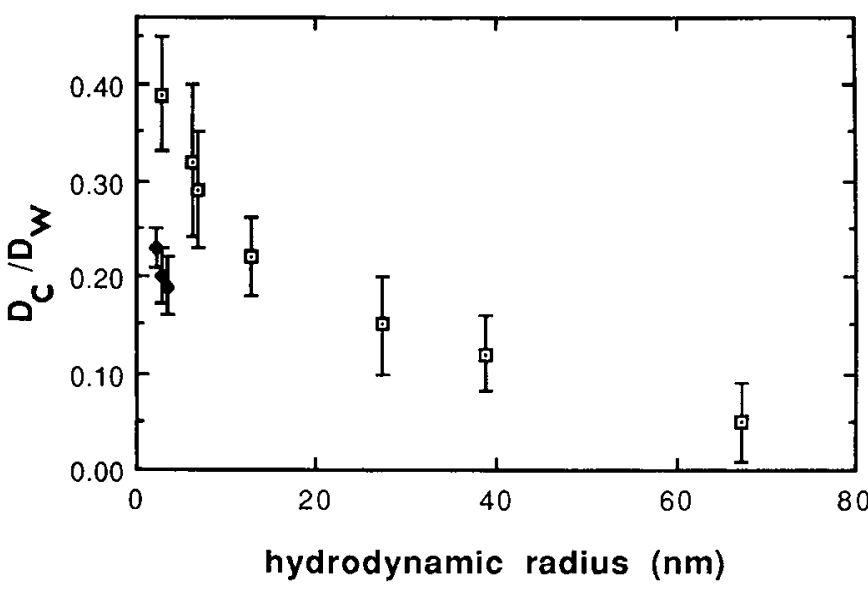

Figure 5. The ratio of diffusion coefficients in neurite cytoplasm to that in aqueous solution for dextran molecules (ㅁ) and globular proteins $(\diamond)$ of different hydrodynamic radii. Note that the ratio for dextrans decreases with increasing radii, suggesting increasing viscosity encountered by larger dextrans in neuronal cytoplasm. Error bars refer to \pm SEM.

dextrans in synapsin I-injected cells was 2.9 times higher than in control cells (Table 3). Control experiments demonstrated that preloading of the neurons with TRITC-dextran alone had no effect on the diffusion of either high or low MW FITCdextrans. Furthermore, the observed effect of synapsin I was not simply due to loading of exogenous protein; $D$ of dextrans was not affected by preloading the neurons with TRITC-conjugated avidin (Table 3 ).

\section{Discussion}

\section{Cytoplasmic viscosity and macromolecular diffusion}

An elaborate microtubule-based system exists in neurons to transport material to and from the distal ends of nerve processes

Table 2. Diffusion coefficients for dextrans in water and in neuronal cytoplasm

\begin{tabular}{|c|c|c|c|}
\hline $\begin{array}{l}\text { Diffusion } \\
\text { coefficient } \\
\text { in water } \\
\left(D_{w}, \mu \mathrm{m}^{2} / \mathrm{sec}\right) \\
\end{array}$ & $\begin{array}{l}\text { Hydro- } \\
\text { dynamic } \\
\text { radius }(\mathrm{nm})\end{array}$ & $\begin{array}{l}\text { Diffusion } \\
\text { coefficient } \\
\text { in nerve } \\
\text { cytoplasm } \\
\left(D_{c}, \mu \mathrm{m}^{2} / \mathrm{sec}\right)\end{array}$ & $D_{c} / D_{w}$ \\
\hline $\begin{array}{l}112.0 \pm 7.2 \\
(11)\end{array}$ & 2.0 & $\begin{array}{l}44.0 \pm 4.1 \\
(9)\end{array}$ & $0.39 \pm 0.06$ \\
\hline $\begin{array}{l}48.1 \pm 3.1 \\
(7)\end{array}$ & 4.6 & $\begin{array}{l}13.0 \pm 2 \\
(6)\end{array}$ & $0.29 \pm 0.06$ \\
\hline $\begin{array}{l}52.2 \pm 6.2^{a} \\
(5)\end{array}$ & 4.2 & $\begin{array}{l}16.6 \pm 2.4 \\
(6)\end{array}$ & $0.32 \pm 0.08$ \\
\hline $\begin{array}{l}29.7 \pm 3.1 \\
(4)\end{array}$ & 8.4 & $\begin{array}{l}6.4 \pm 0.5 \\
(7)\end{array}$ & $0.22 \pm 0.04$ \\
\hline $\begin{array}{l}12.0 \pm 2.4 \\
(6)\end{array}$ & 18.3 & $\begin{array}{l}1.8 \pm 0.3 \\
(9)\end{array}$ & $0.15 \pm 0.05$ \\
\hline $\begin{array}{l}8.5 \pm 0.5 \\
(7)\end{array}$ & 25.8 & $\begin{array}{l}1.0 \pm 0.3 \\
(7)\end{array}$ & $0.12 \pm 0.04$ \\
\hline $\begin{array}{l}4.9 \pm 1.1 \\
(5)\end{array}$ & 44.8 & $\begin{array}{l}0.23 \pm 0.09 \\
(6)\end{array}$ & $0.05 \pm 0.04$ \\
\hline
\end{tabular}

Diffusion coefficients are listed as mean \pm SEM. The numbers in parentheses refer to the number of diffusion experiments analyzed. Effective hydrodynamic radii of various dextrans were calculated from the Stokes-Einstein equation, after $D_{w}$ values were determined experimentally.

${ }^{a}$ TRITC-dextran; all other dextrans were FITC-conjugated. 

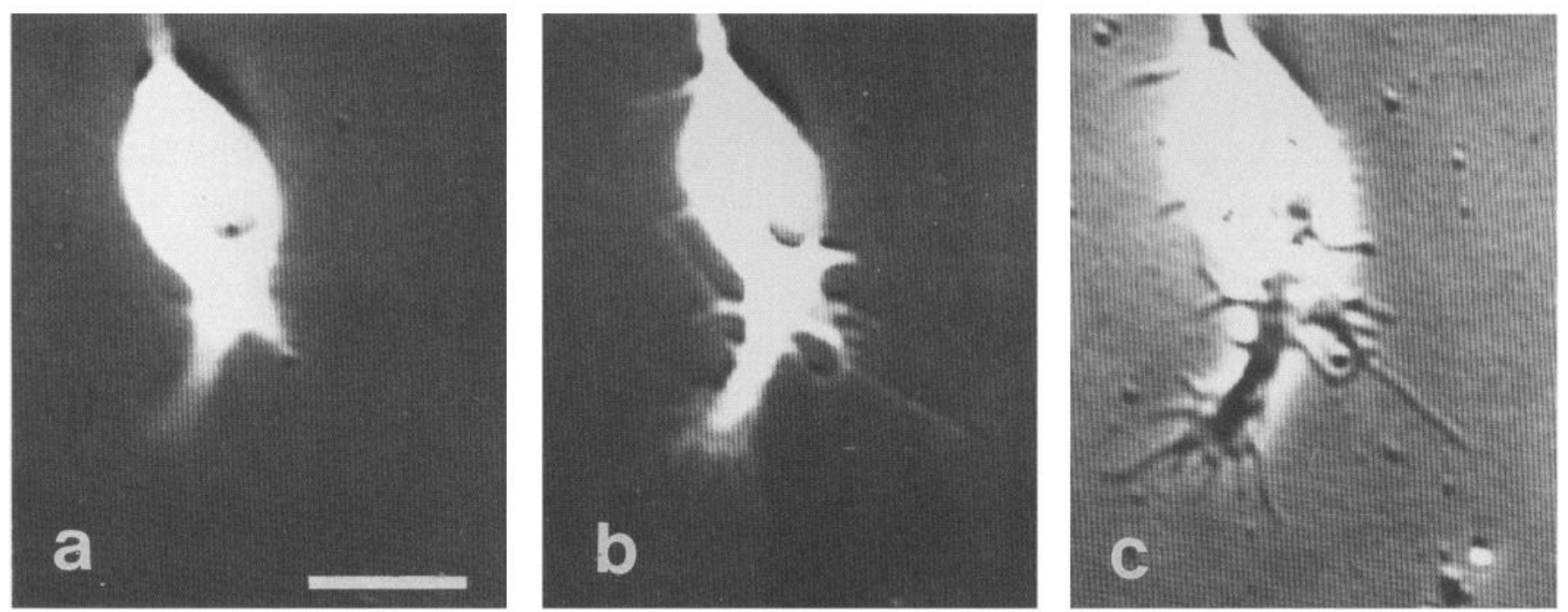

Figure 6. Penetration of large dextrans into fine filopodia processes of the neurite. $a$ and $b$, Fluorescent micrographs taken at 15 sec and 2 min after the pulse injection, respectively. $c$, A phase-contrast micrograph taken 2 min after injection. Note that these large dextran molecules of hydrodynamic radius $25.8 \mathrm{~nm}$ had penetrated into the filopodial processes of the growth cone. Scale bar, $20 \mu \mathrm{m}$.

(Vale, 1987; Okabe and Hirokawa, 1989). For long distances, the rate of diffusional transport is much slower than that of the active transport. However, diffusion can be an effective mechanism to transport macromolecules in short dendrites or in the developing processes with immature transport systems. The rate of diffusional transport of macromolecules in the cell is determined by viscous properties of cell cytoplasm, which have been studied by many biophysical methods (see Luby-Phelps et al., 1988, for review), including electron spin resonance (Mastro et al., 1984), polarization microfluorimetry (Fushimi and Verkman, 1991), observation of the movement of the microinjected magnetic particles (Valberg and Albertini, 1985), fluorescence spectroscopy (Dix and Verkman, 1990), and FRAP (Lanni et al., 1981; Luby-Phelps et al., 1986).

The reported values of viscosity of cytoplasm $\left(\eta_{c}\right)$ are a subject of considerable controversy, since different methods give different values of $\eta_{c}$ for the same cells. Thus, the reported values of $\eta_{c}$ for fibroblasts were 6-13 cP (Burns, 1969), $70 \mathrm{cP}$ (Wojcieszyn et al., 1981), 3-6 cP (Lepock et al., 1983), 3-4 cP (LubyPhelps et al., 1986), 10-13 cP (Dix and Verkman, 1990), 1.2

Table 3. Effects of cytochalasin $B$ and synapsin I on dextran diffusion

\begin{tabular}{lll} 
& $\begin{array}{l}\text { Diffusion coefficient } \\
\text { in neurite cytoplasm } \\
\left(\mu \mathrm{m}^{2} / \mathrm{sec}\right)\end{array}$ \\
\cline { 2 - 3 } $\begin{array}{ll}\text { Small dextran } \\
(r=2.0 \mathrm{~nm})\end{array}$ & $\begin{array}{l}\text { Large dextran } \\
(r=25.8 \mathrm{~nm})\end{array}$ \\
\hline Treatment $^{a}$ & $44 \pm 4(9)$ & $1.0 \pm 0.3(7)$ \\
Control & $36 \pm 5(7)$ & $2.4 \pm 0.4(7)$ \\
Cytochalasin B & $49 \pm 6(6)$ & $2.9 \pm 0.5(6)$ \\
Synapsin I & $38 \pm 7(6)$ & $1.1 \pm 0.4(6)$ \\
TRITC-avidin & $41 \pm 5(3)$ & $1.2 \pm 0.5(7)$ \\
TRITC-dextran, MW 70 K &
\end{tabular}

Diffusion coefficients are listed as mean \pm SEM. The numbers in parentheses refer to the number of diffusion experiments analyzed.

a Control refers to the measurements of dextran diffusion in untreated neurons. The rest of treatments involve loading the neurons with cytochalasin B, synapsin I, TRITC-avidin, or TRITC-dextran prior to the dextran diffusion experiment.
cP (Fushimi and Verkman, 1991). In FRAP experiments, viscosity can be determined by comparing the diffusion coefficient of the probe molecule in the cytoplasm $\left(D_{c}\right)$ with that in the aqueous medium of known viscosity, for example, in water $\left(D_{w}\right)$, that is, $\eta_{c}=\eta_{u} D_{w} / D_{c}$. The viscosity of the cytoplasm, $\eta_{c}$, measured by FRAP was reported to be $2-4 \mathrm{cP}$ for amoeba cells (Wang et al., 1982), 8 cP for embryonic cells of sea urchin (Salmon et al., 1984), $20 \mathrm{cP}$ for hepatocytes (Peters, 1984), and $70 \mathrm{cP}$ for human fibroblasts (Wojcieszyn et al., 1981). In some cases, the same probe molecules were used (Peters, 1984; LubyPhelps et al., 1986) and discrepancy in $\eta_{c}$ probably reflects differences in the organization of cytoplasm between cell types. On the other hand, different $\eta_{c}$ values obtained by FRAP measurements on the same cell strongly indicate that the model of cell cytoplasm as a homogeneous viscous medium (Newtonian liquid) is not valid; the inferred viscosity depends on the probe molecule.

It has been shown in erythrocytes that lateral diffusion of membrane proteins is restrained by membrane-attached cytoskeleton. Disruption of cytoskeletal structures led to $100-1000$ fold increase in the $D$ value of some membrane proteins (Koppel et al., 1981). Previous reports also indicated that cytoskeleton can impose some limitation on the macromolecular diffusion in the cytoplasm as well (Wojcieszyn et al., 1981; Mastro et al., 1984). It was suggested that observed differences in $\eta_{c}$ values measured by different methods are due to different sizes of the probe molecules (Luby-Phelps et al., 1987), which interact differently with cytoskeletal structures.

\section{Cytoskeletal constraint on diffusion}

Various components of the cytoskeleton system - microtubules, microfilaments, intermediate filaments, and small $(2-3 \mathrm{~nm}$ in diameter) filaments of poorly defined composition - form a dense interconnected meshwork in the cytoplasm called the cytoplasmic matrix or ground substance (Hubbard and Lazarides, 1979; Schliwa and van Blerkom, 1981; Bridgman and Reese, 1984; Katsuma et al., 1987; Tint et al., 1991). The mesh size of this system was estimated to be $70-100 \mathrm{~nm}$ from the analysis of 
electron micrographs (Porter, 1984). It is reasonable to expect that cytoplasmic matrix can impose a size limit for unrestricted diffusion of molecules or organelles within the cytoplasm (Gershon et al., 1985).

The properties of this cytoskeletal meshwork can be studied in the reconstituted system, using purified cytoskeletal proteins (Flory, 1956; Hitt et al., 1990; Kerst et al., 1990). A number of properties of the reconstituted system may be relevant to understanding of cytoskeletal constraint on diffusion. The actin filaments demonstrated flexible motions in actin gels (Schmidt et al., 1989). The viscoelastic properties of reconstituted systems can be modified by actin- or tubulin-binding proteins (Wang and Singer, 1977; MacLean-Fletcher and Pollard, 1980; Hou et al., 1990; Janmey et al., 1990), and diffusion coefficient of probe molecules in gels depends on the size of the molecules (Newman et al., 1989; Hou et al., 1990). Thus, the cytoskeletal meshwork is a flexible system, in which diffusional restriction can be modified. The mobility of large components in the cytoplasm probably depends upon the degree of flexibility in the cytoskeletal meshwork.

\section{Diffusion in nerve processes}

In conventional FRAP measurements, nonuniform distribution of probe molecules is created by bleaching fluorescent molecules in small areas (a few micrometers in diameter). A value of $D$ is determined from the recovery of fluorescence in the bleached area. For nerve cells, diffusion over longer distances is more physiologically relevant. To measure the $D$ values for macromolecules, we have injected small amounts of FITC- or TRITClabeled molecules into the soma of the neuron and monitored diffusional spread of the molecules along neurites up to $200 \mu \mathrm{m}$ long, using a video imaging method. The diffusion of injected molecules from soma to axon has been previously measured for small radioactively labeled molecules in Aplysia axons up to 10 mm long (Koike and Nagata, 1979). The latter method has a spatial resolution of $\sim 1 \mathrm{~mm}$ and allows one to measure diffusion of small ( $\sim 1 \mathrm{~nm}$ in diameter) molecules in axons. The method that we report is applicable to the diffusion of molecules of any size in native nerve processes.

We found that $D$ values of BSA, ovalbumin, and lactalbumin in neurite cytoplasm were approximately five times lower than that in aqueous solution. No statistically significant dependence of $D$ on the size of the proteins was found over the narrow size range of 2-3 $\mathrm{nm}$. In order to examine diffusional transport of molecules over a wider range of sizes, we chose fluorescently labeled dextrans as probe molecules, which are available in molecular weights that range over 3 orders of magnitude. An additional advantage of dextran molecules is that apparently they do not interact with cytoplasmic structures (Paine and Horowitz, 1980; Luby-Phelps et al., 1986).

By comparing the diffusion rate of dextrans in neurites versus that in the aqueous solution, we found that inferred viscosity of the neurite cytoplasm depended on the size of the dextran molecule. It increased from 2.6 to $20 \mathrm{cP}$ for dextrans of effective radii from 2.0 to $44.8 \mathrm{~nm}$. This effect cannot be explained by a high concentration of proteins in the cytoplasm. Previous studies on the diffusion of dextrans in concentrated protein solutions have shown that the inferred viscosity of the solution depends only weakly on the size of the dextran (Luby-Phelps et al., 1986). Similar results were reported for the diffusion of globular proteins in concentrated solution of macromolcculcs (Phillies, 1985; Ullman et al., 1985). In any case, the strong size dependence we observed cannot be explained by nonideal behavior of probe molecules in a concentrated solution of proteins.

To assess directly the role of cytoskeleton in the rate of macromolecular diffusion, we treated the cells with the microfilament-disrupting drug cytochalasin B (Cooper, 1987). Statistically significant increase of $D$ for large MW dextrans $(r=25.8$ $\mathrm{nm})$ was found, while that of small dextrans $(r=2.0 \mathrm{~nm})$ was unchanged. This result suggests that diffusion of large molecules in the neuronal cytoplasm is restricted by actin cytoskeleton. We also preloaded neurons with dephosphorylated synapsin I protein that has actin-bundling activity (Bahler and Greengard, 1987). Again, we found that diffusion of large dextrans was increased. This effect is similar to the increasc of diffusion ratc of large ficolls in reconstituted actin system upon addition of actin-binding protein filamin (Hou et al., 1990). Both of these findings can be explained by an increase in the average mesh size of cytoskeletal system resulting from the bundling of actin filaments by actin-binding proteins.

The result of cytochalasin B and synapsin I treatments, together with the size dependence of diffusion rates, provides some information on the size and flexibility of cytoskeletal meshwork in these developing neurites. Dextrans are highly flexible branched polymers, whose behavior in solution can be described by a random-coil polymer model (Ogston and Woods, 1953; Basedow and Ebert, 1979). We deduced the effective hydrodynamic radius of the dextran from the Stokes-Einstein equation. To characterize pore permeability of dextrans, the radius of gyration, $r_{g}$ (Tanford, 1961; Mohrer et al., 1984), is a more appropriatc parameter. It has becn found that $r_{g}$ of random-coil polymer differs from its hydrodynamic radius deduced from the Stokes-Einstein equation by a factor of $1.5\left(r_{g}=1.5 r\right)$. From the above result on the effect of cytochalasin and synapsin I, we may conclude that diffusion of macromolecules of a $r_{g}$ about 40 $\mathrm{nm}$ is significantly affected by the cytoskeletal structures, suggesting a mesh size as small as $80 \mathrm{~nm}$. However, long-range diffusion, although greatly retarded, was observed even for the largest dextran $\left(r_{g}=70 \mathrm{~nm}\right)$, indicating that the cytoskeletal meshwork is flexible and does not impose a rigid restriction on diffusion.

\section{Implications for molecular transport in neurons}

The characteristic time $t$ required for a typical globular protein $(70 \mathrm{~K})$ to diffuse to the distal end of a dendritic process $L \mu \mathrm{m}$ long can be roughly estimated as $t=L^{2} / D_{c}$, where $D_{c}$ is the diffusion coefficient of molecules in a neuronal cytoplasm. A 70 $\mathrm{K}$ protein has a hydrodynamic radius of approximately $3.5 \mathrm{~nm}$ and a $D_{w}$ in aqueous solution of $60 \mu \mathrm{m}^{2} / \mathrm{sec}$. Assuming no association of the protein with other cytoplasmic components, our result on the dextran diffusion (Fig. 3) predicts that $D_{c}$ should be about three times lower than the $D_{w}$. Thus, $D_{c} \sim 20 \mu \mathrm{m}^{2} / \mathrm{sec}$ and the characteristic time $t$ to reach $L=200 \mu \mathrm{m}$ is $t \sim 30 \mathrm{~min}$. Note that this is a lower limil estimate, since any association of the molecules with other cytoplasmic components will increase the time. As shown by our results on protein diffusion in neurites, all three proteins studied appeared to diffuse about $60 \%$ slower than expected, suggesting a weak association of the proteins with cytoplasmic components.

Diffusion of globular proteins in the neurite cytoplasm is about five times slower than in aqueous solution, while in fibroblasts it was reported to be 70 times slower (Wojcieszyn et al., 1981). Thus, the information concerning cytoplasmic organization of the fibroblast cannot be readily extrapolated to the nerve cell. 
It has been proposed that the mesh in actin cytoskeleton is less than the diameter of microtubules $(22 \mathrm{~nm})$, based on the exclusion of microtubules from the growth cone (Forscher and Smith, 1988) and the exclusion of large polymers from the lamellipodia of fibroblasts (Luby-Phelps et al., 1988). In contrast to the latter finding, we found that large dextrans $\left(r_{g}=38.7 \mathrm{~nm}\right)$ do penetrate to the distal end of growth cone filopodia. This indicates that the actin cytoskeleton meshwork at the growth cone is less dense or more flexible than previously expected, based upon the analogy between the growth cone and lamellar protrusions of fibroblasts.

Several specific proteins and mRNA have been found to be localized within different domains of cultured neurons (Binder et al., 1986; Banker and Waxman, 1988; Bruckenstein et al., 1990; Kleiman et al., 1990). Regional localization within the neuron could result from either directional active transport or diffusion-driven movement, followed by selective trapping of the component at the specific region. Our observation that large inert macromolecules do spread efficiently throughout nerve cytoplasm suggests that diffusional movement is an efficient process for short-range transport. In cultured neurons that show distinct differentiation of axonal versus dendritic processes (Banker and Cowan, 1979), selective diffusion barrier at the axonal hillock could be responsible for the formation of axonal versus soma-dendritic domains. Our observation that modulation of actin microfilaments alters the diffusion of large dextrans suggests that this cytoskeletal structure may play a part in forming such diffusion barriers.

Neurite cytoskeletal elements form a dense and highly crosslinked filamentous network (Schnapp and Reese, 1982). The speed of the active transport has been found to be inversely related to the size of the organelles, and this size dependence may reflect steric interactions of the transported organelles with the cytoskeleton (Willard et al., 1974; Hirokawa, 1982; Vale et al., 1985). Our results not only directly demonstrate the sizedependent interaction of macromolecules with cytoskeleton but also provide a quantitative basis for an estimate of the viscous drag encountered by a particle of given size in the nerve cytoplasm, in both diffusional and active transports.

\section{References}

Anderson MJ, Cohen MW (1977) Nerve-induced and spontaneous redistribution of acetylcholine receptors on cultured muscle cells. J Physiol (Lond) 268:757-773.

Bahler M, Greengard P (1987) Synapsin I bundles F-actin in a phosphorylation-dependent manner. Nature 326:704-707.

Banker GA, Cowan WM (1979) Further observation on hippocampal neurons in dispersed cell culture. J Comp Neurol 187:469-494.

Banker GA, Waxman AB (1988) Hippocampal neurons generate natural shapes in cell culture. In: Intrinsic determinants of neuronal form and function (Lasek RJ, Black MM, eds), pp 288-321. New York: Liss.

Basedow AM, Ebert KH (1979) Production, characterization and solution properties of dextran fractions of narrow molecular weight distributions. J Polym Sci Polym Simp 66:101-115.

Binder LI, Frankfurter A, Rebhun LI (1986) Differential localization of MAP2 and tau in mammalian neurons in situ. Ann NY Acad Sci 466:145-166.

Bridgman PC, Reese TS (1984) The structure of cytoplasm in directly frozen cultured cells. I. Filamentous meshworks and the cytoplasmic ground substance. J Cell Biol 99:1655-1668.

Bruckenstein DA, Lein PJ, Higgins D, Fremeau RT Jr (1990) Distinct spatial localization of specific mRNAs in cultured sympathetic neurons. Neuron 5:809-819.
Burns VW (1969) Measurement of viscosity in living cells by a fluorescence method. Biochem Biophys Res Commun 37:1008-1014.

Cooper JA (1987) Effects of cytochalasin and phalloidin on actin. J Cell Biol 105:1473-1478.

Crank J (1975) The mathematics of diffusion. Oxford: Clarendon.

Dix JA, Verkman AS (1990) Mapping of fluorescence in living cells by ratio imaging. Application to cytoplasmic viscosity. Biophys J 57: 231-240.

Flory PJ (1956) Phase equilibrium in solutions of rod-like particles. Proc R Soc Edinburgh [Sect A] 234:73-89.

Forscher P, Smith SJ (1988) Actions of cytochalasins on the organization of actin filaments and microtubules in a neuronal growth cone. J Cell Biol 107:1505-1516.

Fushimi K, Verkman AS (1991) Low viscosity in the aqueous domain of cell cytoplasm measured by picosecond polarization microfluorimetry. J Cell Biol 112:719-725.

Gershon ND, Porter KR, Trus BL (1985) The cytoplasmic matrix: its volume and surface area and the diffusion of molecules through it. Proc Natl Acad Sci USA 882:5030-5034.

Graessmann A, Graessmann M, Mueller C (1980) Microinjection of early SV 40 DNA fragments and T antigen. Methods Enzymol 65: 816-825.

Hamill OP, Marty A, Neher E, Sakmann B, Sigworth FJ (1979) Improved patch-clamp techniques for high-resolution current recording from cells and cell-free membrane patches. Pfluegers Arch 391:85100.

Hirokawa N (1982) Cross-linker system between neurofilaments, microtubules and membranous organelles in frog axon revealed by the quick-freeze, deep-etching method. J Cell Biol 94:129-142.

Hitt AL, Cross AR, Williams RCJ (1990) Microtubule solutions display nematic liquid crystalline structure. J Biol Chem 256:1639-1647.

Hou L, I uby-Phelps K, I anni F (1990) Brownian motions of inert tracer macromolecules in polymeric and spontaneously bundled mixtures of actin and filamin. J Cell Biol 110:1645-1654.

Hubbard B, Lazarides E (1979) Copurification of actin and desmin from chicken smooth muscle and their copolymerization in vitro to intermediate filaments. J Cell Biol 80:166-182.

Janmey PA, Hvidt S, Lamb J, Stossel TP (1990) Resemblance of actinbinding protein/actin gels to covalently crosslinked networks. Nature 345:89-92.

Katsuma Y, Swierenga SH, Marceau N, French SW (1987) Connections of intermediate filaments with nuclear lamina and the cell periphery. Biol Chem 59:193-203.

Kerst A, Chmielewski C, Livesay C, Buxbaum EE, Heidemann SR (1990) Liquid crystal domains and thixotropy of filamentous actin suspensions. Proc Natl Acad Sci USA 87:4241-4245.

Kleiman R, Banker G, Steward O (1990) Differential subcellular localization of particular mRNAs in hippocampal neurons in culture. Neuron 5:821-830.

Koike $H$, Nagata $Y$ (1979) Intra-axonal diffusion of $\left[{ }^{3} \mathrm{H}\right]$ acetylcholine and $\left[{ }^{3} \mathrm{H}\right] \gamma$-aminobutyric acid in a neurone of $A$ plysia. J Physiol (Lond) 295:397-417.

Koppel DE, Sheetz MP, Schindler M (1981) Matrix control of protein diffusion in biological membranes. Proc Natl Acad Sci USA 76:35763580 .

Lanni F, Ware BR, Taylor DL (1981) Fluorescence photobleaching recovery in solutions of labeled actin. Biophys J 35:351-364.

Lepock JR, Cheng K-H, Campbell SD, Kruuv J (1983) Rotational diffusion of tempore in the cytoplasm of Chinese hamster lung cells. Biophys J 44:405-412.

Luby-Phelps K, Taylor DL, Lanni F (1986) Probing the structure of cytoplasm. J Cell Biol 102:2015-2022.

Luby-Phelps K, Castle PE, Taylor DL, Lanni F (1987) Hindered diffusion of inert tracer particles in the cytoplasm of mouse 3T3 cells. Proc Natl Acad Sci USA 84:4910-4913.

Luby-Phelps K, Lanni F, Taylor DL (1988) The submicroscopic properties of cytoplasm as a determinant of cellular function. Annu Rev Biophys Chem 17:369-396.

MacLean-Fletcher SD, Pollard TD (1980) Viscometric analysis of the gelation of Acanthamoeba extracts and purification of the gelation factors. J Cell Biol 85:414-428.

Mastro AM, Babich MA, Taylor WD, Keith AD (1984) Diffusion of a small molecule in the cytoplasm of mammalian cells. Proc Natl Acad Sci USA 81:3414-3418.

Mohrer MP, Patterson GD, Carrol PJ (1984) Hindered diffusion of 
dextran and ficoll in microporous membranes. Macromolecules 17: 1170-1173.

Newman J, Mroczka N, Schick KL (1989) Dynamic light scattering measurements of the diffusion of probes in filamentous actin solutions. Biopolymers 28:655-666.

Ogston AG, Woods EF (1953) Molecular configuration of dextrans in aqueous solution. Nature 171:221-222.

Okabe S, Hirokawa N (1989) Axonal transport. Curr Opinions Cell Biol 1:91-97.

Paine PL, Horowitz SB (1980) The movement of material between nucleus and cytoplasm. In: Cell biology: a comprehensive treatise, Vol 4 (Goldstein L, Prescott DM, eds), pp 299-338. New York: Academic.

Peters R (1984) Nucleo-cytoplasmic flux and intracellular mobility in single hepatocytes measured by fluorescence microphotolysis. EMBO J 3:1831-1836.

Phillies GDJ (1985) Diffusion of bovine serum albumin in neutral polymer solution. Biopolymers 24:379-386.

Porter KR (1984) The cytomatrix: a short history of its study. J Cell Biol 99(1, pt 2):3s-12s.

Radomsky ML, Whaley KJ, Cone RA, Saltzman WM (1990) Macromolecules released from polymers: diffusion into unstirred fluids. Biomaterials 11:619-624.

Salmon ED, Saxton WM, Leslie RJ, Karow ML, McIntosh JR (1984) Diffusion coefficient of fluorescently-labeled tubulin in the cytoplasm of embryonic cells of a sea urchin: video image analysis of fluorescence distribution after photobleaching. J Cell Biol 99:2157-2164.

Sanes DH, Poo M-m (1989) In vitro analysis of position- and lineagedependent selectivity in the formation of the neuromuscular synapses. Neuron 2:1237-1244.

Schliwa M, van Blerkom J (1981) Structural interaction of cytoskeletal components. J Cell Biol 90:222-235.

Schmidt CH, Baermann M, Isenberg G, Sackmann E (1989) Chain dynamics, mesh size, and diffusive transport in networks of polymeric actin. A quasielastic light scattering and microfluorescence study. Macromolecules 22:3638-3649.

Schnapp VJ, Reese TS (1982) Cytoplasmic structure in rapid-frozen axons. J Cell Biol 94:667-679.

Spitzer NC, Lamborghini JC (1976) The development of the action potential mechanism of amphibian neurons isolated in culture. Proc Natl Acad Sci USA 73:1461-1465.

Spring KR, Lowy RJ (1989) Characteristics of low light level television cameras. Methods Cell Biol 29:269-289.

Stollberg J, Fraser SE (1988) Acetylcholine receptors and concavalin A-binding sites on cultured Xenopus muscle cells: electrophoresis, diffusion, and aggregation. J Cell Biol 107:1397-1408.

Tabti N, Poo M-m (1991) Culturing Xenopus nerve and muscle cells. In: Cultures of nerve cells (Banker G, Goslin K, eds), pp 137-153. Boston: MIT Press.

Tanford C (1961) Physical chemistry of macromolecules. New York: Wiley.

Tint IS, Hollenbeck PJ, Verkhovsky AB, Surgucheva IG, Bershadsky $A D$ (1991) Evidence that intermediate flament reorganization is induced by ATP-dependent contraction of the actomyosin cortex in permeabilized fibroblasts. J Cell Sci 98:375-384.

Ullman GS, Ullman K, Linder RN, Phillies GDJ (1985) Probe diffusion of polystyrene latex spheres in poly(ethylene oxide)-water. $\mathrm{J}$ Phys Chem 89:692-700.

Valberg PA, Albertini DF (1985) Cytoplasmic motions, rheology and structure probed by a novel magnetic particle method. J Cell Biol 101:130-140.

Vale RD (1987) Intracellular transport using microtubule-based motors. Annu Rev Cell Biol 3:347-378.

Vale RD, Schnapp BJ, Reese TS, Sheetz MP (1985) Organelle, bead, and microtubule translocation promoted hy soluble factors from the squid giant axon. Cell 40:559-569.

Wang K, Singer SJ (1977) Interaction of filamin with F-actin in solution. Proc Natl Acad Sci USA 74:2021-2025.

Wang Y-L, Lanni F, McNeil PL, Ware BR, Taylor DL (1982) Mobility of cytoplasmic and membrane-associated actin in living cells. Proc Natl Acad Sci USA 79:4660-4664.

Willard M, Cowan WM, Vagelos PR (1974) The polypeptide composition of intra-axonally transported proteins: evidence for four transport velocities. Proc Natl Acad Sci USA 71:2183-2187.

Wojcieszyn JW, Schlegel ESW, Jacobson KA (1981) Diffusion of injected macromolecules within the cytoplasm of living cells. Proc Natl Acad Sci USA 78:4407-4410. 